\title{
Health information seeking on the Internet: a double divide? Results from a representative survey in the Paris metropolitan area,
} France, 2005-2006 Emilie Renahy* ${ }^{\dagger 1,2}$, Isabelle Parizot ${ }^{\dagger 1,2}$ and Pierre Chauvin ${ }^{\dagger 1,2,3}$

Address: ${ }^{1}$ INSERM, U707, Research Team on the Social Determinants of Health and Healthcare, Paris, F-75012, France, ${ }^{2}$ Université Pierre et Marie Curie-Paris6, UMR-S 707, Paris, F-75012, France and 3AP-HP, Hôpital Saint Antoine, Department of Public Health, Paris, F-75012, France

Email: Emilie Renahy* - renahy@u707.jussieu.fr; Isabelle Parizot - parizot@u707.jussieu.fr; Pierre Chauvin - chauvin@u707.jussieu.fr

* Corresponding author †Equal contributors

Published: 21 February 2008

BMC Public Health 2008, 8:69 doi:10.1 I86/147|-2458-8-69

This article is available from: http://www.biomedcentral.com/I47/-2458/8/69

(C) 2008 Renahy et al; licensee BioMed Central Ltd.

This is an Open Access article distributed under the terms of the Creative Commons Attribution License (http://creativecommons.org/licenses/by/2.0), which permits unrestricted use, distribution, and reproduction in any medium, provided the original work is properly cited.
Received: 28 August 2007

Accepted: 21 February 2008

\begin{abstract}
Background: The Internet is a major source of information for professionals and the general public, especially in the field of health. However, despite ever-increasing connection rates, a digital divide persists in the industrialised countries. The objective of this study was to assess the determinants involved in: I) having or not having Internet access; and 2) using or not using the Internet to obtain health information.
\end{abstract}

Methods: A cross-sectional survey of a representative random sample was conducted in the Paris metropolitan area, France, in the fall of $2005(n=3023)$.

Results: Close to $70 \%$ of the adult population had Internet access, and $49 \%$ of Internet users had previously searched for medical information. Economic and social disparities observed in online health information seeking are reinforced by the economic and social disparities in Internet access, hence a double divide. While individuals who reported having a recent health problem were less likely to have Internet access (odds ratio (OR): 0.72 , 95\% confidence interval (Cl): $0.53-0.98$ ), it is they who, when they have Internet access, are the most likely to search for health information (OR $=1.44,95 \% \mathrm{Cl}=1.1 \mathrm{I}-1.87)$.

Conclusion: In the French context of universal health insurance, access to the Internet varies according to social and socioeconomic status and health status, and its use for health information seeking varies also with health beliefs, but not to health insurance coverage or health-care utilisation. Certain economic and social inequalities seem to impact cumulatively on Internet access and on the use of the Internet for health information seeking. It is not obvious that the Internet is a special information tool for primary prevention in people who are the furthest removed from health concerns. However, the Internet appears to be a useful complement for secondary prevention, especially for better understanding health problems or enhancing therapeutic compliance. 


\section{Background}

The Internet access rate has continued to increase in all industrialised countries over the past 15 years, having climbed recently to 54\% in France and 70\% in the United States [1]. The Internet is now a major information tool, both in people's professional and private lives. However, several studies report the existence of a persistent digital divide both in Internet access [2-4] and Internet use [5]. Such is the context in which a large number of general public health-related websites and discussion groups have been created. Many studies have been carried out to describe the characteristics of people who use the Internet to obtain health information. Most of them indicate that the discriminating factors are age, level of education, level of income and ethnicity [6]. Online health seekers are more likely to be young, to have a higher level of education, a higher level of income, and to be white (in the United States). The same differences have been shown for Internet access as such [2-4]. Other studies have also suggested an association with long-term illness [7], reported chronic conditions [8] or a greater health concern [9]. Moreover, some researchers have suggested that online health information especially benefits the already privileged in terms of health, health-care utilisation or socioeconomic status [10-12]. Some patient population-based studies, have led to a better understanding of the circumstances of online health information seeking in terms of the stage of an illness $[13,14]$. Other studies also debate the actual benefits of the Internet in general and online discussion groups in terms of the social support (positive most of the time $[15,16]$, but there is no robust evidence [17]).

Most of these studies have involved patients with specific diseases (e.g., cancer or HIV infection) or small and/or nonrandom samples. Moreover, many of them are purely descriptive or examine only one explanatory dimension, and none of them have been conducted in France [6]. The probable cumulative impact of barriers to the Internet access and, consequently, to the use of the Internet for health purposes has not, as such, often been studied. Empirical studies are starting to take into consideration more broadly the cognitive barriers to the general public's use of the Internet for health information seeking, including the different skills required to read, use new technologies, search for information, and understand health information (e-health literacy) [18,19]. It seemed important to us to statistically analyze in the same representative population-based survey (and especially in the French context of universal health insurance) the factors associated with Internet access and the use of the Internet to search for health information, both potentially involving common skills and determinants.
The objectives of this study were to describe and compare the determinants involved in: 1) having or not having Internet access; and 2) using or not using the Internet to obtain health information (within the Internet user population). To answer these questions as accurately as possible, several hypotheses were proposed. Apart from the usual characteristics for evaluating the association with demographics and socioeconomic status, we simultaneously tested the potential effect of health status, health perceptions and behaviours, health-care system utilisation, social integration, psychological capital, living conditions, and lastly, technological skills.

\section{Methods \\ Study sample}

The SIRS (French acronym for health, inequalities and social ruptures) survey was conducted in the fall of 2005 in a representative sample of the adult French-speaking population in the Paris metropolitan area (Paris and its suburbs, a region with a population of 6.5 million). This survey constituted the first phase of a socio-epidemiological cohort study in the general population, a collaborative research project between the French National Institute for Health and Medical Research, National Centre for Scientific Research and National Institute for Demographic Studies. The sampling was carried out in three stages. We used a geographical partition of the Paris metropolitan area, specifically, the smallest unit area available in the French statistical data system (each neighbourhood has approximately 2000 inhabitants). We first used the Surveyselect procedure (SAS ${ }^{\circledast}$ V9.1) to randomly select 50 neighbourhoods (overrepresenting the poorer neighbourhoods [20]). We then randomly selected households in each neighbourhood. Lastly, we selected the interviewees by the birthday method. No incentives were offered. On the contrary, the survey was clearly presented as a voluntary one conducted by a public research institute. The interviewers were required to visit each household eight times at different dates and times before scratching it off and replacing it with another (chosen at random). Twenty-one percent of the "original" households had to be replaced after eight visits because there was no one at those addresses. In all, 29\% of the people contacted declined to answer the survey and 5\% were excluded because they did not speak French $(3 \%)$ or because they were too sick to answer our questions (2\%). A questionnaire was administered in person during home visits to a random sample of 3023 people. Data on numerous social and health-related characteristics were collected, as well as answers to a specific module of questions on Internet use.

\section{Variables of interest}

Two outcomes were defined for this study. For Internet use, we considered the fact of personally having gone online, regardless of the location (Yes/No). We subse- 
quently identified among the respondents who had gone onto the Internet those who had used it at least once in the previous three years (Yes/No) to search for information on any of the following health-related topics: medical news, treatment centres, hospitals or physicians, a particular disease or treatment, alternative medicines, or healthrelated administrative measures. In this paper, health is therefore to be understood in its 'medical' sense (the concepts of nutrition or, more generally, well-being were not listed among the topics selected for our purposes here), while online sources were considered globally, without making any distinction between professional or general public sites.

\section{Explanatory variables}

In addition to age and gender, we distinguished between French people born of two French parents, those born of at least one foreign parent, and foreigners in order to take a certain amount of cultural diversity into account. The respondents' socioeconomic status was characterised by the following variables: level of monthly household income (range: $60-10,000 €$ per consumption unit; quartile values: 1055/1600/2380), level of education, occupational status and health insurance status. The monthly household income was calculated with the OECD standard method to assess the financial status of people, taking account of the size and composition of households. We added up the individual incomes of all the members of the household. We then divided this sum by an adjusted number of people living in the household or "consumption unit". This number was as follows: the reference person in the household (the one with the highest SES) was assigned a value of 1 , every other person over 14 years of age a value of 0.5 , and children under 14 a value of 0.3 [21]. With regards occupational status, we differentiated between those who were active (in France, a person is considered active if he or she is working or looking for work), those who were inactive (retired or with no profession), and students. One question on the perception of financial difficulties and another on difficulty reading French rounded out this assessment of socioeconomic status.

Social integration was measured in terms of both family and social integration: civil status (lives or does not live in a couple relationship), number of children, and status in the support network. An individual was considered a "helper" if he or she had helped someone financially or by providing moral support or assistance in daily living during the previous six months; "helped" if he or she had received such help without giving any in return; or "isolated" from the support network if he or she had not given or received any help in the previous six months.

To discern disease experience, we took into consideration the respondents' health status (recent and past) and that of their close relatives. An individual was considered to have been sick in the recent past if he or she reported having had at least one chronic problem in the previous 12 months (based on a preestablished list of the main chronic problems commonly used in other health surveys in France, such as asthma, diabetes, hypertension, cancer, etc. [22]) and/or as being treated or followed on a regular basis for medical reasons and/or as having a disability or handicap. A past disease experience was defined as a report of a chronic problem (on the same list) prior to the previous 12 months and/or a report of "serious health problems" before the age of 18 years. As for the health status of close relatives, we distinguished between a past experience (an illness in the spouse and/or a serious health problem in the parents before the age of 18 years) and a present experience (an illness or a handicap in a member of the household and/or in a close relative on the day of the survey). This different approach for the time frame for measuring health among self and others is due to using secondary data and based upon the available questions.

Additionally, declarative data on different characteristics were collected in order to understand the potential effect of health-care system utilisation: having a regular physician, having been or a close relative having been the victim of a medical error (during lifetime), having used traditional medicine, or having forgone medical care for financial reasons during the previous 12 months.

The respondents' psychological status was evaluated on the basis of the following elements: the presence of an anxiodepressive syndrome on the day of the survey (score determined by the MINI-Diag questionnaire [23], a 10item questionnaire exploring the presence of problems such as sadness, fatigue, a depressed feeling, a loss of appetite, sleeping disorders, a loss of self-confidence, and so on during the last two weeks, and then dichotomised in a binary depression variable - Cronbach's alpha value of 0.60 for the 10 -items and 0.73 for the 3 first ones used as conditional response); perceived mental health on the day of the survey ("In general, would you say that your psychological and emotional health is very good, good, somewhat good, fair or poor?"); and self-esteem (score on the Rosenberg Self-Esteem Scale [24] - Cronbach's alpha $=0.83$ - expressed in terms of a quartile) .

The respondents were asked about their health perceptions [25] and beliefs about medicine and fate. With regard to perceptions, they were asked about three dimensions: resistance to illness ("My body seems to resist illness very well."), health outlook ("In the future, I expect to have better health than other people I know."), and health worry ("I worry about my health more than other people worry about theirs."). As for beliefs, two questions 
were asked: "Do you think that medicine has effective solutions to all health problems?" and "Do you think that disease and healing depend on God, fate or providence?". Lastly, we considered whether or not they thought that "information provided by physicians is difficult to understand" or that "health advice and recommendations are difficult to apply in daily life". All the variables were dichotomised between "Yes" (if the respondent was strongly or somewhat in agreement with the statement) and "No" (if he or she was strongly or somewhat in disagreement).

Lastly, the Internet users were asked whether they had a home connection, how often they used the Internet (low versus high, low being defined as every month or less often, high as every day or week) and for how long they had been using it (in years).

\section{Statistical methods}

Since we did not have an a priori hypothesis, we decided to estimate the models that fit our data and explain the outcomes the best. The variables potentially associated with the different outcomes were selected one by one, on the basis of "univariate" logistic regression models systematically adjusted for gender, age, level of education and level of income. All the variables significant at a threshold of 0.20 (Wald test) were entered into a multivariate model. We then selected the best model by a manual step-by-step backward procedure (threshold of significance set at 0.05) [26]. We tested all the plausible interaction (but none were found to be significant). We also calculated the Cox and Snell generalized coefficient of determination and the Nagelkerke adjusted coefficient of determination (reaching a maximum of 1 ) to assess the proportion of variance explained by the final model [27] and the area under the receiver operating characteristic (ROC) curve to provide a more easily interpretable criterion of our model assessment.

All of these statistical analyses were weighted in order to take into account the sampling technique (3-stage sample: census tracts, households and individuals, with initial overrepresentation of the disadvantaged areas) and the poststratification adjustment for age and gender according to the general population census data [28]. The Surveylogistic procedure $\left(\mathrm{SAS}^{\circledast} \mathrm{V}\right.$ V.1) was used to take this weighting into account when estimating the parameters, confidence intervals and statistical tests. Lastly, to assess the stability of our results, an automated logistic regression and variable selection procedure was carried out on 200 bootstrap samples generated from our initial sample [29].

\section{Results}

The participation rate in the survey was $71 \%$. The sample consisted of 1423 men (47.1\%) and 1600 women $(52.9 \%)$. With regard to socioeconomic status, $65.9 \%$ were active, $27.2 \%$ were inactive and $6.9 \%$ were students. The median age was 42 years (interquartile range: $30-58$ ). The distribution of the weighted sample by gender, age and socio-occupational status was representative of the adult population in the Paris metropolitan area.

\section{Internet access}

Close to $70 \%$ of the respondents had previously personally gone online. We did not consider for this analysis the covariates that pertain to the following dimension: health-care utilisation, health perceptions and Internet use. Although men $(73 \%)$ seemed to have greater access to the Internet than women (67\%), the difference was not significant (Table 1). On the other hand, Internet access decreased significantly with increasing age and increased with the level of education and income. These disparities were reinforced by the perception of financial difficulties and difficulties reading French. When adjusted for all the variables in the model, the French respondents with French parents had a greater likelihood of previously having gone online than those with foreign parents or than foreigners. Individuals with inactive occupational status had less access to the Internet than those with active status, while students had greater access. In addition, the probability of having used the Internet was significantly greater in individuals who were healthy and well integrated into the support network. The generalized and adjusted coefficients of determination in the final model (respectively, $\mathrm{R}^{2}=0.43$ and $\widetilde{\mathrm{R}}^{2}=0.61$ ) and the area under the ROC curve ( $c=0.907$ ) showed that the model had very-good-quality prediction and discrimination. In the 200 bootstrap samples, the 10 variables in the model presented here (the four adjustment variables were not taken into account) were the 10 most frequently selected variables (including seven with a frequency greater than $70 \%$ ).

\section{Use of the Internet to search for health information}

The most common source of health information mentioned by the survey's respondents was their physician (77\% consulted a physician "quite often" or "in most cases" when they had a health question), while $34.2 \%$ of the total - or $48.5 \%$ of the Internet users - indicated that they had searched for medical information online during the previous three years.

The final multivariate model did not show, among Internet users, an association between health information 
Table I: Internet access: multivariate logistic regression (Number of observations $=\mathbf{3 0 2 3}$ )

\begin{tabular}{|c|c|c|c|c|}
\hline & $\%$ of sample & aOR* & $95 \% \mathrm{Cl}$ & $\mathbf{P} * *$ \\
\hline Gender & & & & 0.761 \\
\hline Men & 47.1 & I & - & \\
\hline Women & 52.9 & 0.96 & $0.74-1.25$ & \\
\hline Age group (years) & & & & $<0.0001$ \\
\hline$>59$ & 22.5 & I & - & \\
\hline $45-59$ & 23.7 & 4.49 & $2.83-7.12$ & \\
\hline $30-44$ & 30.4 & 11.72 & $7.16-19.19$ & \\
\hline$<30$ & 23.4 & 23.99 & $13.33-43.16$ & \\
\hline Level of education & & & & $<0.0001$ \\
\hline None/Primary & 9.7 & I & - & \\
\hline Secondary & 38.9 & 3.31 & $2.08-5.29$ & \\
\hline Postsecondary & 51.4 & 14.99 & $9.10-24.71$ & \\
\hline Monthly household income (€/CU) & & & & $<0.0001$ \\
\hline |st quartile & 25.0 & I & - & \\
\hline $2^{\text {nd }}$ quartile & 25.9 & 1.55 & $1.12-2.16$ & \\
\hline $3^{\text {rd }}$ quartile & 24.2 & 2.78 & $1.82-4.25$ & \\
\hline $4^{\text {th }}$ quartile & 24.9 & 3.45 & $2.14-5.58$ & \\
\hline Occupational status & & & & $<0.0001$ \\
\hline Active & 65.9 & 1 & - & \\
\hline Inactive & 27.2 & 0.41 & $0.27-0.61$ & \\
\hline Student & 6.9 & 3.57 & $1.02-12.63$ & \\
\hline Nationality & & & & 0.002 \\
\hline French/French parents & 68.4 & I & - & \\
\hline French/Foreign parents & 17.7 & 0.79 & $0.56-1.13$ & \\
\hline Foreign & 13.9 & 0.49 & $0.33-0.72$ & \\
\hline Perception of having financial difficulties & & & & 0.008 \\
\hline No & 55.0 & I & - & \\
\hline Yes & 45.0 & 0.68 & $0.51-0.90$ & \\
\hline Difficulty reading French & & & & $<0.0001$ \\
\hline No & 91.8 & I & - & \\
\hline Yes & 8.2 & 0.26 & $0.16-0.43$ & \\
\hline Social integration & & & & $<0.0001$ \\
\hline Isolated & 16.7 & I & - & \\
\hline Helped & 6.2 & 1.33 & $0.73-2.43$ & \\
\hline Integrated & 77.1 & 2.60 & $1.89-3.59$ & \\
\hline Current health problem(s) & & & & 0.036 \\
\hline No & 30.3 & I & - & \\
\hline Yes & 69.7 & 0.72 & $0.53-0.98$ & \\
\hline
\end{tabular}

* Adjusted odds ratio

** Overall P_value based on the Type III Wald statistic

seeking and occupational status, nationality, financial difficulties or difficulties reading French. We still observed significant associations with age, level of income, level of education, and social integration (Table 2). Actually, the level of education is globally significant in our study (even though none of the education levels were found to be significant). When this variable is dichotomised (postsecondary education versus the other two levels combined), the effect is indeed highly significant (odds ratio (OR) = $1.65,95 \%$ confidence interval $(\mathrm{CI})=1.25-2.17$ ), and estimates of other parameters do not differ. The final model also showed that women were significantly more likely to have previously searched for health information than men $(\mathrm{OR}=1.64,95 \% \mathrm{CI}=1.29-2.07)$. In addition, Internet users who were sick or who had a poor perception of their mental health were more likely to have previously searched for health information online (respectively, OR $=1.44,95 \% \mathrm{CI}=1.11-1.87$, and $\mathrm{OR}=1.41,95 \% \mathrm{CI}=$ 1.05-1.91). The same was true for individuals who had a close relative with a health problem at the time of the survey. More generally, worrying about one's health more than most people or having difficulty understanding information provided by physicians was positively associated with online health information seeking. Lastly, experience with the Internet (regular use, home connection, and number of years with Internet access) significantly 
Table 2: Use of the Internet for health information seeking: multivariate logistic regression (Number of observations = 193 I)

\begin{tabular}{|c|c|c|c|c|}
\hline & $\%$ of Internet users & aOR* & $95 \% \mathrm{Cl}$ & $\mathbf{P} * *$ \\
\hline Gender & & & & $<0.0001$ \\
\hline Men & 49.0 & 1 & - & \\
\hline Women & 51.0 & 1.64 & I.29-2.07 & \\
\hline Age group (years) & & & & $<0.001$ \\
\hline$>59$ & 10.6 & I & - & \\
\hline $45-59$ & 22.8 & 1.54 & $1.01-2.36$ & \\
\hline $30-44$ & 36.2 & 1.81 & $1.19-2.75$ & \\
\hline$<30$ & 30.4 & 2.73 & $1.71-4.38$ & \\
\hline Level of education & & & & 0.001 \\
\hline None/Primary & 1.4 & I & - & \\
\hline Secondary & 32.5 & $\mathrm{I} .47$ & $0.60-3.60$ & \\
\hline Postsecondary & 66.1 & 2.39 & $0.97-5.85$ & \\
\hline Monthly household income (€/CU) & & & & 0.020 \\
\hline |st quartile & 25.6 & 1 & - & \\
\hline $2^{\text {nd }}$ quartile & 24.5 & 1.62 & $1.17-2.24$ & \\
\hline $3^{\text {rd }}$ quartile & 24.8 & 1.59 & $1.10-2.29$ & \\
\hline $4^{\text {th }}$ quartile & 25.1 & 1.39 & $0.94-2.05$ & \\
\hline Social integration & & & & $<0.001$ \\
\hline Isolated & 12.0 & I & - & \\
\hline Helped & 4.9 & 1.51 & $0.79-2.88$ & \\
\hline Integrated & 83.1 & 2.31 & $1.54-3.47$ & \\
\hline Lives in a couple relationship & & & & 0.020 \\
\hline No & 37.8 & 1 & - & \\
\hline Yes & 62.2 & 1.35 & $1.05-1.73$ & \\
\hline Current health problem(s) & & & & 0.007 \\
\hline No & 34.9 & I & - & \\
\hline Yes & 65.1 & $\mathrm{I} .44$ & $1.11-1.87$ & \\
\hline Relative with current health problem(s) & & & & 0.002 \\
\hline No & 48.3 & I & - & \\
\hline Yes & 51.7 & 1.44 & $1.14-1.82$ & \\
\hline Perception of mental health & & & & 0.024 \\
\hline Good & 18.7 & 1 & - & \\
\hline Poor & 81.3 & 1.41 & $1.05-1.91$ & \\
\hline Worries about health more than others & & & & 0.040 \\
\hline No & 75.9 & I & - & \\
\hline Yes & 24.1 & 1.32 & $1.01-1.7 \mid$ & \\
\hline Difficulties understanding information from GP & & & & 0.049 \\
\hline No & 52.2 & I & - & \\
\hline Yes & 47.8 & 1.27 & $1.01-1.60$ & \\
\hline Frequency of Internet use & & & & $<0.0001$ \\
\hline Low & 22.2 & 1 & - & \\
\hline High & 77.8 & 2.96 & $2.15-4.07$ & \\
\hline Home connection & & & & 0.014 \\
\hline No & 21.4 & 1 & - & \\
\hline Yes & 78.6 & 1.47 & $1.08-1.99$ & \\
\hline Years with access & & & & $<0.001$ \\
\hline$<1$ & 12.9 & I & - & \\
\hline $1-3$ & 28.9 & 1.37 & $0.94-2.02$ & \\
\hline $4-6$ & 35.7 & 1.63 & $1.11-2.4 \mid$ & \\
\hline$>7$ & 22.5 & 2.45 & $1.60-3.76$ & \\
\hline
\end{tabular}

* Adjusted odds ratio

** Overall P_value based on the Type III Wald statistic

increased this specific use. With generalized and adjusted coefficients of determination of $0.20\left(\mathrm{R}^{2}\right)$ and $0.25\left(\widetilde{R}^{2}\right)$, respectively, and an area under the ROC curve of 0.73 , the model's prediction quality was acceptable. In addition, the variables are those found most often in bootstrap modelling (eight variables in more than $65 \%$ of the cases). 


\section{Discussion}

These analyses performed on a representative random sample of the population of the Paris metropolitan area confirm the main factors (age, level of income and education) discriminating Internet use in the general population on the one hand $[2,3,30,31]$ and Internet use for seeking answers to health questions in the Internet user population on the other [7,32-34]. Our study shows simultaneously - in a single representative sample of the general population - an association with the three variables mentioned above for both outcomes. Researchers sometimes present ethnicity as a factor associated with health information seeking [35]. In France, it is illegal to ask people for their ethnicity, but it is allowed to ask for their nationality. Even if both do not explore the same dimensions, obviously, our data show that nationality is associated with Internet access but no longer with health information seeking among Internet users. In addition, new discriminating factors were observed. Specifically, our analyses show that social isolation is associated with a lower probability of Internet use. In the subsample of Internet users, women, people concerned about a health problem (their own or that of a close relative), those worried about their health or those who had difficulty understanding advice from physicians were more likely to have previously sought health information online than the others. The same is true for the individuals who were well integrated socially and who had Internet experience.

Even if the random sample from the Paris metropolitan area exhibits good representativeness, these results cannot be extended to the entire population of France because the Paris metropolitan area has specific characteristics not shared by the rest of the country. On average, its inhabitants are younger and have a higher level of education and a higher socio-occupational status [36]. Certain contextual factors themselves are different. Urban density, physician density [37] and the high-speed Internet connection rate [2] are notably higher there than in the other parts of France.

In addition, certain analyses performed on this sample of 3023 people may have suffered from a lack of statistical power because of the small sample size in some of the subgroups. However, the modelling performed on the 200 bootstrap samples generated from the initial sample shows that the results presented here are robust and satisfactorily adjusted to the data.

Our study confirms that the Internet penetration rate is higher in the Paris metropolitan area than it is nationally. Close to $60 \%$ of the respondents had a home connection, and $70 \%$ had previously personally gone online. In another national survey, the same rates were observed in Paris, while the estimates for France as a whole were respectively $43 \%$ and $54 \%$ during the same survey year [30]. These estimates are of the same order of magnitude as in all the other countries with high Internet penetration rates (65 to $75 \%$ in the United States, Japan and Sweden, for example [1]).

Furthermore, this study shows the existence, in the Paris metropolitan area, of a digital divide previously identified in France $[2,30]$ and in other industrialised countries $[4,31]$. The probability of having Internet access decreases with age but increases with the level of education and income. The gender effect sometimes reported in Europe or the United States [38,39] was not observed in our study. These disparities are reinforced by the individuals' perception of their own socioeconomic situation. For a given level of education and income, the probability of having Internet access is lower in cases where there are perceived financial problems. Lastly, difficulty reading French also seems to be a barrier to Internet use. In general, people who do not have Internet access are those who have the least favourable social and economic characteristics: low income, no or few degrees, unemployed, foreign nationality and social isolation. Yet, these populations are also recognised as being more on the fringes of the health-care system and in less good health [40-42]. In our study, when adjusted for all of the socioeconomic characteristics, sick people also use the Internet less than others.

The analysis performed on the subsample of Internet users shows that nearly $49 \%$ of the individuals surveyed had previously searched online for information on a health-related topic during the previous three years. It is difficult to compare this estimate with those in other studies because the definition of the term "health" or the time period considered differs substantially from study to study. In late 2005, 28\% of the Internet users in France had used the Internet to search "for information on health, a disease or diet and nutrition during the previous month" [30], while $58 \%$ of Norwegians [43] or $71 \%$ of European Internet users [7] had previously conducted online searches "for health purposes". In the United States, even though the total number of Internet users increased between 2004 and 2006, the proportion of "health seekers" remained stable (around 80\% of American Internet users) [44].

With regard to socioeconomic status, certain determining factors of Internet access also discriminate health information seeking within the Internet user population itself. As has been shown in several international studies (often by descriptive or univariate analyses), the probability of having used the Internet to obtain health information decreases with age but seems to increase with the level of education and income [6]. On the other hand, the effect 
of the level of income seemed to distinguish between households with the poorest quartile of income and the others. While both the reported level of income and the subjective perception of financial difficulties, as well as occupational status, nationality and origin were factors discriminating Internet access, the second analysis revealed a significant association only between health information seeking and the actual level of household income. The data did not show a significant association with the subjective perception of one's socioeconomic status, occupational status or nationality.

As in other studies $[7,30,33,34]$ (although some of them report discordant results [45]), our results show that women Internet users are the most active online health seekers. In general, women can be considered the ones who usually look after health matters in their families [46]. Although our data do not show a significant association with the number of children, a positive relationship is observed with living in a couple relationship or there being a sick individual in one's close circle. The gender effect appears perhaps to manifest as a different level of interest in health.

Some authors suggest that, in fact, the health information available online particularly benefits the already privileged in terms of health and health-care utilisation and/or the well-educated [10-12]. Indeed, a European study found that the probability of health information seeking grows with the number of visits to a physician [7]. In the French context of universal health insurance, our multivariate analysis did not show the four variables concerning health-care system utilisation or health insurance coverage to have a significant effect. On the other hand, our analyses did show strong associations between Internet use for seeking answers to health questions and health status, experiences and perceptions. As some studies tend to show with perceived health status $[47,48]$ or long-term illness $[7,8]$, the probability of previously having searched for health information online was greater in people who were sick and in those with a poor perception of their mental health status and/or who had a close relative with an illness. A positive association was found among individuals who feel that they worry more about their health than others, which confirms the notion in a previous American study which found that health seekers were "more likely to be health-oriented" [9]. As for health status (reported), the opposite effect was observed for our first outcome. While the sick were less likely to have Internet access, it was they who, among the Internet users, used this tool more often to obtain health information. The Internet therefore seems to be an important informationseeking tool for people dealing with an illness, when they have an opportunity to go online.
To understand and interpret our results more globally, we can refer to the concept of eHealth literacy $[18,19]$, which combines the dimensions that underlie health literacy (functional, critical and interactive) [49] and online skills [50]. Although having reading difficulties appears to be a barrier to Internet use, we did not observe any effect associated with health information seeking in the Internet user population. The analysis of each of the outcomes shows postsecondary education to have a positive effect. Several studies do, in fact, show that the contents of healthrelated websites are written in a language geared to a high level of education [11].

All factors otherwise being equal (and especially for a given level of education), the probability of having used the Internet to seek answers to health questions is greater in individuals who find information provided by physicians difficult to understand. On the other hand, having difficulty applying health advice in daily life (adjusted only for gender, age, level of education and level of income) no longer appears to be significantly associated with online health information seeking in the final model. It may thus be asked to what extent the Internet is useful to people with poor health literacy.

Lastly, a double socioeconomic divide was previously reported in another study concerning Internet access and general Internet use (but not specifically health information seeking) [31]. Our data show that similar factors (age, level of education and level of income) are associated both with Internet access and the use of the Internet for health information searching. Furthermore, our study shows that Internet experience has a positive effect. Health information seeking appears to be more common when the frequency of use and the number of years of Internet use is higher. It seems that, with experience, the Internet assumes an increasingly important role in Internet users' lives in terms of how they obtain information and can even become an integral part of their daily lives. Searching on the Internet would thus become a habit or even an automatic reflex when searching for any information in general, just as when searching for health information in particular.

\section{Conclusion}

In the context of France's universal health insurance program and of high physician density in the Paris metropolitan area, access to the Internet varies according to social and socioeconomic status and health status, and its use for health information seeking varies also with health beliefs, but not to health insurance coverage or healthcare utilisation. Certain social and economic inequalities seem to impact cumulatively on Internet access and on its use to seek health information. The analyses performed on a representative sample from the Paris metropolitan 
area show that the most disadvantaged social groups and those the least integrated socially use the Internet less and, in the Internet user population itself, are again those that seek health information on the Internet the least.

We found that people who would need the Internet the most as a potential source of health information - to compensate for a lack of information or for remoteness from the health-care system (difficult economic circumstances, social isolation, health problems) - are also those who use it the least. Among Internet users, those furthest removed from health concerns (the non-sick or the less health-concerned) search for health information online less. It is therefore not obvious that the Internet is a special information tool for primary prevention. On the other hand, for patients and individuals who have difficulty understanding information provided by physicians, the Internet appears to be a useful complement for secondary prevention, especially for better understanding health problems or enhancing therapeutic compliance.

\section{Competing interests}

The author(s) declare that they have no competing interests.

\section{Authors' contributions}

ER participated in conceiving and designing the study and in acquiring the data, performed analyses, interpreted the results, and participated in drafting and revising the manuscript. IP participated in conceiving and designing the study and revised the manuscript. PC participated in conceiving and designing the study, in interpreting the results and in revising the manuscript. All three authors approved the final manuscript.

\section{Acknowledgements}

The SIRS survey was supported by the French National Institute for Health and Medical Research (INSERM), the Institute for Public Health Research (IRSP), the Directorate-General of Health (DGS), the Interministerial Delegation for Urban Affairs (DIV), the European Social Fund, the Regional Council of lle-de-France, and the City of Paris. This study was part of a research project supported by a grant from the French Ministry of Research.

\section{References}

I. Internet World Stats [http://www.internetworldstats.com/]

2. Bigot R: La diffusion des technologies de l'information dans la société française [Information and communication technology diffusion in French society]. In Enquête "Conditions de vie et Aspirations des Français" (survey) Paris , Crédoc; 2006.

3. Demunter C: Fracture numérique en Europe [Digital divide in Europe]. Statistiques en bref, Eurostat [http://epp.euro stat.ec.europa.eu/cache/ITY OFFPUB/KS-NP-05-038/FR/KS-NP-05038-FR.PDF].

4. Irving L, Klegar-Levy K, Everette DW, Reynolds T, Lader W: Falling through the Net: Defining the digital divide. Washington, DC , National Telecommunications and Information Administration, US Department of Commerce; 1999.

5. Hargittai E: Internet access and use in context. New Media and Society 2004, 6(I):137-I43.
6. Renahy E, Chauvin P: Internet uses for health information seeking: a literature review. Rev Epidemiol Sante Publique 2006, 54:263-275.

7. Andreassen HK, Bujnowska-Fedak MM, Chronaki CE, Dumitru RC Pudule I, Santana S, Voss H, Wynn R: European citizens' use of Ehealth services: A study of seven countries. BMC Public Health 2007, 7(I):53.

8. Bundorf MK, Wagner TH, Singer SJ, Baker LC: Who searches the internet for health information? Health Serv Res 2006, 4I(3, Part I):819-836.

9. Dutta-Bergman MJ: Health attitudes, health cognitions, and health behaviors among Internet health information seekers: Population-based survey. J Med Internet Res 2004, 6(2):el5.

10. Eng TR, Maxfield A, Patrick K, Deering MJ, Ratzan SC, Gustafson DH: Access to health information and support: a public highway or a private road? Jama 1998, 280(15): I37|-I375.

II. Gilmour JA: Reducing disparities in the access and use of Internet health information. A discussion paper. Int J Nurs Stud 2007, 44(7): 1270-1278.

12. Korp P: Health on the Internet: implications for health promotion. Health Educ Res 2006, 21 (1):78-86.

13. Nabarette H: L'Internet médical et la consommation par les patients [The medical Internet and consumption by patients]. Réseaux 2002, II 4:.

14. Ziebland S, Chapple A, Dumelow C, Evans J, Prinjha S, Rozmovits L: How the Internet affects patients' experience of cancer: a qualitative study. BMJ 2004, 328(7439):564.

15. Drentea P, Moren-Cross JL: Social capital and social support on the web: the case of an internet mother site. Sociol Health IIIn 2005, 27(7):920-943.

16. Fogel J, Albert SM, Schnabel F, Ditkoff BA, Neugut AI: Internet use and social support in women with breast cancer. Health Psychol 2002, 2 I (4):398-404.

17. Eysenbach G, Powell J, Englesakis M, Rizo C, Stern A: Health related virtual communities and electronic support groups: Systematic review of the effects of online peer to peer interactions. BMJ 2004, 328(7449): I 166.

18. Norman CD, Skinner HA: eHEALS: the eHealth literacy scale. J Med Internet Res 2006, 8(4):e27.

19. Norman CD, Skinner HA: eHealth literacy: essential skills for consumer heath in a networked world. J Med Internet Res 2006, 8(2):e9.

20. Préteceille E: La division sociale de l'espace francilien [Social division in the Paris metropolitan area]. Paris, Observatoire sociologique du changement; 2003.

21. Consumption unit Definition \& Methodology [http://www.insee.fr/ fr/nom def met/definitions/html/unite-consommation.htm].

22. Auvrey L, Dumesnil S, Le Fur P: Les maladies et les troubles de santé déclarés. Santé, soins et protection sociale [IIIness and reported health issues. Health, healthcare and social protection]. Paris, CREDES; 200I.

23. Sheehan $\mathrm{V}$, Lecrubier $\mathrm{Y}$, Sheehan $\mathrm{KH}$, Amorim $\mathrm{P}$, Janavs J, Weiller $\mathrm{E}$, Hergueta T, Baker R, Dunbar GC: The Mini-International Neuropsychiatric Interview (M.I.N.I.): the development and validation of a structured diagnostic psychiatric interview for DSM-IV and ICD-I0. J Clin Psychiatry 1998, 59(20):22-33.

24. Rosenberg M: Society and the adolescent self-image. Princeton , Princeton University Press; 1965.

25. Ware JE: The health perceptions questionnaire. In Measuring health $A$ guide to rating scales and questionnaires 2 nd edition. New York , Oxford University Press; 1976:21 9-225.

26. Hosmer D, Lemeshow S: Applied logistic regression. 2nd Ed. New York, Wiley; 2000.

27. Nagelkerke NJD: A note on a general definition of the coefficient of determination. Biometrika I99I, 78(3):69I-692.

28. Sautory O: La macro Calmar. Redressement d'un échantillon par calage sur marges [Calmar: an SAS ${ }^{\circledR}$ macro for poststratification adjustments]. [http://www.insee.fr/frl nom def met/outils stat/calmar/cal res.htm].

29. Efron B, Tibshirani RJ: An introduction to the Bootstrap. New York, Chapman and Hall; 1993.

30. Frydel $Y$ : Internet au quotidien : un Français sur quatre [Daily Internet: one Frenchman in four]. In Insee Première Paris, Institut national de la statistique et des études économiques; 2006.

31. Hargittai E: Second-level digital divide: Differences in people's online skill. First Monday 2002, 7(4): 
32. Pandey SK, Hart JJ, Tiwary S: Women's health and the Internet: understanding emerging trends and implications. Soc Sci Med 2003, 56(I): 179-191.

33. Rice RE: Influences, usage, and outcomes of Internet health information searching: Multivariate results from the Pew surveys. Int J Med Inform 2006, 75(I):8-28.

34. Ybarra ML, Suman M: Help seeking behavior and the Internet: A national survey. Int J Med Inform 2006, 75(I):29-4I.

35. Lorence DP, Park H, Fox S: Racial disparities in health information access: resilience of the Digital Divide. J Med Syst 2006, 30(4):24I-249.

36. Ile-de-France : la région en faits et chiffres [Paris and the surrounding departments: facts and figures] Chiffres-clés [http:// www.insee.fr/fr/insee regions/idf/rfc/accueil $\mathrm{rfc}$.asp].

37. Hilico C, Poulos D: Les départements métropolitains : similitudes et oppositions socio-économiques [Metropolitan departments: socioeconomic similarities and differences]. In Insee Première Paris, Institut national de la statistique et des études économiques; 2004.

38. Wilson KR, Wallin JS, Reiser C: Social stratification and the Digital Divide. Soc Sci Comput Rev 2003, 2 I(2): | 33- | 43.

39. Losh SC: Gender, educational, and occupational digital gaps 1983-2002. Soc Sci Comput Rev 2004, 22(2):152-166.

40. Davey Smith G: Health inequalities. Lifecourse approaches. Bristol , The Policy Press; 2003.

4l. Lurie N, Dubowitz T: Health disparities and access to health. Jama 2007, 297(10): I I I8-II2I.

42. Marmot M, Wilkinson R: Social determinants of health. 2nd edition. Oxford , Oxford University Press; 2005.

43. Hege KA, Silje CW, Rolf W, Tove S, Per H: Health-related use of the Internet in the Norwegian population. Tidsskr Nor Laegeforen 2006, I 26(22):2950-2952.

44. Fox S: Online health search 2006. Washington DC, Pew Internet \& American Life Project; 2006.

45. Spadaro R: Eurobarometer 58.0. European Union citizens and sources of information about health. The European Opinion Research Group (EORG); 2003:16.

46. Cresson G: Le travail domestique de santé. In Logiques sociales Paris, L'Harmattan; 1998.

47. Houston TK, Allison J]: Users of Internet health information: Differences by health status. J Med Internet Res 2002, 4(2):e7.

48. Fogel J, Morgan PD, Davis BL: Consumers of Internet health information and self-rated health status: Breast care disparities issues. J Multicultural Nurs Health 2005, I I (3):35-40.

49. Gray NJ, Klein JD, Sesselberg TS, Cantrill JA, Noyce PR: Adolescents' health literacy and the Internet. J Adolesc Health 2003, 32(2): 124.

50. Hargittai E: Survey measures of web-oriented digital literacy. Soc Sci Comput Rev 2005, 23(3):37I-379.

\section{Pre-publication history}

The pre-publication history for this paper can be accessed here:

http://www.biomedcentral.com/1471-2458/8/69/prepub
Publish with Bio Med Central and every scientist can read your work free of charge

"BioMed Central will be the most significant development for disseminating the results of biomedical research in our lifetime. "

Sir Paul Nurse, Cancer Research UK

Your research papers will be:

- available free of charge to the entire biomedical community

- peer reviewed and published immediately upon acceptance

- cited in PubMed and archived on PubMed Central

- yours - you keep the copyright
BioMedcentral 